\title{
The Use of Remote Sensing and Gis in Mineral Prospecting Of Toro and Environs (Bauchi State)
}

\author{
${ }^{* 1}$ Aluwong K. C., ${ }^{2}$ Bala, D. A., ${ }^{3}$ Kamtu, P. M. and ${ }^{4}$ Nimchak, R. N. \\ ${ }^{I}$ Dept. of Mining Engineering, Faculty of Engineering, University of Jos \\ ${ }^{2}$ Dept. of Science Laboratory Technology, Faculty of Natural Science, University of Jos \\ ${ }^{3}$ Dept. of Mechanical Engineering, Faculty of Engineering, University of Jos \\ ${ }^{4}$ Dept. of Geology, Faculty of Natural Science, University of Jos
}

\begin{abstract}
Remote sensing and Geographic Information System (GIS) application was carried out in the Geological Mapping and Mineral prospecting of Toro and Environs, Bauchi State.Tectonic mapping showed that structures generally trend NE-SW and NW-SE in line with the principal fracture direction on the Basement Complex. The rivers and vegetation of Toro and Environs are generally structurally controlled.The results revealed the importance of image processing which was carried out in the following order; Image Enhancement, Clustering/Classification, Supervised classification, Image ratio, Tectonic mapping approach, Vegetation (Geobotanical) and Digital Terrain Modeling. Economic mineral potential zone of the Toro and Environs include DogoDaji, Duste Moro, Panshanu others are Juga, Buri, Leru and JarawanKogi. Economic minerals found within Toro and Environs are Cassiterite, Topaz, Aqua marine, Zircon, Columbite.
\end{abstract}

\section{Introduction}

Mineral targeting entails the utilization of geological attributes that control their emplacement. Locating these geological controls is usually viewed within the framework of the parameters that are associated with the depositional and post depositional processes that have affected them. Exploration methods are usually designed to take care of the peculiarities of all observable surface geological evidences that can be utilized to identify areas of probable mineralization. The use of Landsat remote sensing, is aimed at digitally manipulating the information stored in the imagery in other to extract those that can be directly linked to the surface processes such as weathering and alterations that are associated with mineral deposits. All the geologically related information generated from the imagery form the database for a GIS - based extraction of the most promising areas. Specific attributes that were considered useful for exploration of the Geology and Mineral Potential of Toro and Environs is the rock outcrops and lineaments concentration. This is a direct product of the probable mineralized area as well as vegetation cover indicating healthy plant growth cause of soil fertility as a result of soil enrichment with minerals. In a situation where the exposures are poor, mapping usually involves indirect methods such as; Inference from geological mapping, Structural evidences, Geochemical evidencesand Geophysical evidences.

Location of the Area The area is about 60kilometer southwest of Bauchi Capital of Bauchi State, between metric grid coordinates between 500554.37 to 527554.49 and 1105629.11 to 1133101.25 which corresponds to Latitudes $10^{\circ} 00^{\prime} \mathrm{N}$ to $10^{\circ} 15^{\prime} \mathrm{N}$ and Longitudes $9^{0} 00^{\prime} \mathrm{E}$ to $9^{0} 15^{\prime} \mathrm{E}$ (Fig. 1).

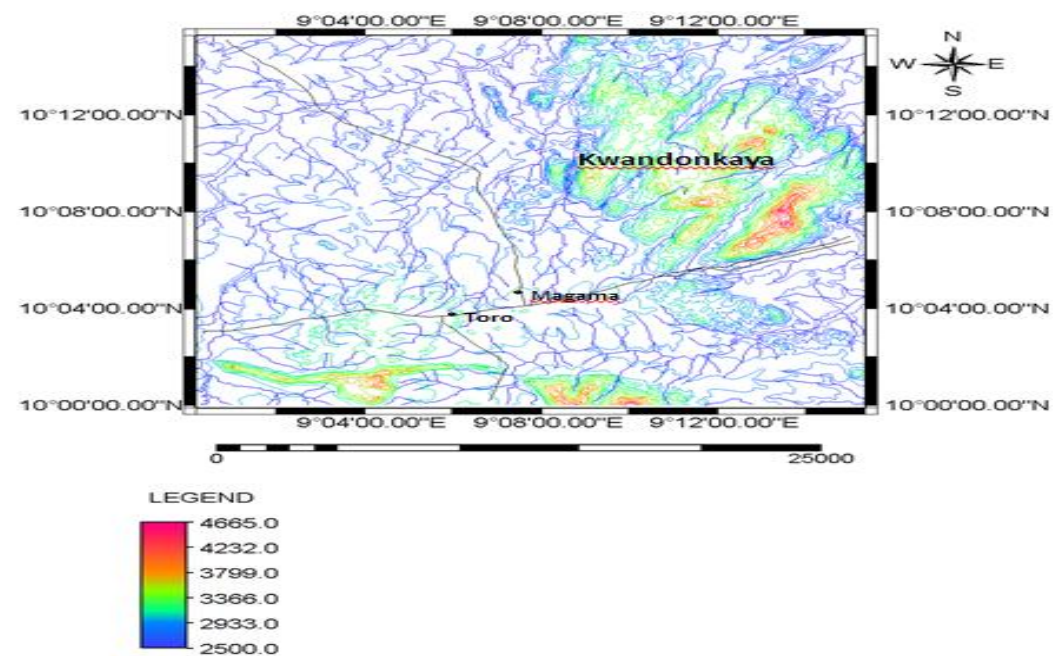

Fig. 1 Map of the Toro and Environs showing areas of highest peak. 


\section{Relief and Drainage}

The general elevation of the terrain is between $6920 \mathrm{~m}$ (Bauchi plains) to the east of $16141 \mathrm{~m}$ (Ziem Peak) above sea level. Kwandonkaya complex is situated about 40km north-east of Jos, forming a prominent hill mass with an area of $118.4 \mathrm{~km}^{2}$. Large areas covered by flat slabs with widely spaced jointing lie at an elevation of 2076-2422m above the plains, with marginal tors rising a further $1384 \mathrm{~m}$. To the south of the Panshanu Pass, a narrow prolongation of the complex, about 2 miles wide, extends for $8 \mathrm{~km}$ towards the Kofai Hills.

The area is well drained, there is more runoff than percolation, and the drainage pattern is dendritic. Most of the streams flow in a NW-SE direction which is perhaps structurally controlled. There are many seasonal streams. Important streams include the River Jarawa, River Nahuta and also River Juga whose outlets spread across the northern to the south-central of the mapped area. The Chief river of the Kwandonkaya massif occupies the wide flat Juga valley, which provides easy access for the road to Juga Mining Camp near the centre of the complex.

\section{Basis for the Application of Lansat 7 Etm Data for Mineral Exploration}

Spectra of weathered iron minerals usually show weak reflectance in the blue region (band1) and strong reflectance in the red region (band3)(Sabins, 1987).

Band5 responds to variations in ferric iron $\left(\mathrm{Fe}_{2} \mathrm{O}_{3}\right)$ content in rocks and soils, which show higher reflectances as the iron content increases. Band7 likewise reacts to moisture contents and is especially suited to detecting hydrous minerals (such as clays or certain alteration products) in geologic settings (Drury 1990 and Sabins 1987). Band6 can distinguish a radiant temperature difference of about $0.6^{\circ} \mathrm{C}$ and is helpful in discriminating rock types whose thermal properties show differences in temperatures near their surface. In this study, band 6 was not used because of the difference in the spatial resolution with the other bands.

Clay mineral kaolinite show marked absorption features near 1.5 and 2.2 microns (fig. 2) which correspond to Landsat_7 ETM bands 5 and 7 respectively while limonite show lower reflectance near the visible red and increased reflectance in the infra-red bands.

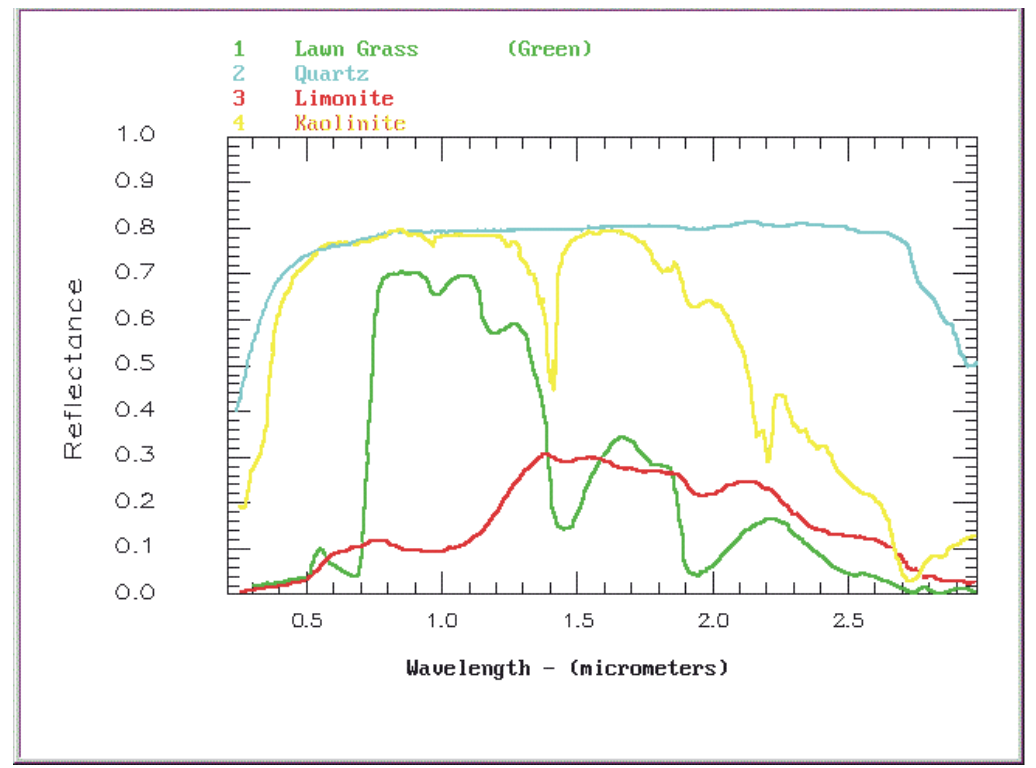

Fig.2 Comparison of reflectance of grass and the minerals quartz, kaolinite and limonite in the region from 0.2

\section{Geology of Kwandonkaya}

to $3.0 \mu($ www.biogeorecon.com $)$

The Kwandonkaya Complex is entirely granitic in composition and no evidence of any earlier volcanic activity is preserved. The two most important units are both biotite-granite of contrasting grain size and texture. A third biotite-granite shows considerable variation in texture throughout its extent and probably represents a hybrid of the two earlier phases as its contacts with these intrusions are for the most part indeterminate and transitional (Bul 32 Vol.I).

Relics of two earlier intrusions of hornblende-fayalite and hornblende-biotite-granite are preserved as roof pendants at Ziem Peak and Dabbolungu respectively. The present conFig.uration of the Dagga Allah porphyry and of its attendant dyke swarms suggests that they have been obliterated over a considerable area by the later granites of the Kwandonkaya Complex and it is possible that the pendant of hornblende-fayalite-granite on Ziem Peak formed part of a horizontal sheet associated with the porphyry (fig. 3). The cycle of intrusion in the complex may be summarized as follows: 
a. Panshanu biotite

b. Porphyry biotite-granite

c. Medium-grained biotite-granite

d. Panshanu biotite-granite

e. Hornblende-biotite-granite

f. Hornblende-fayalite-granite

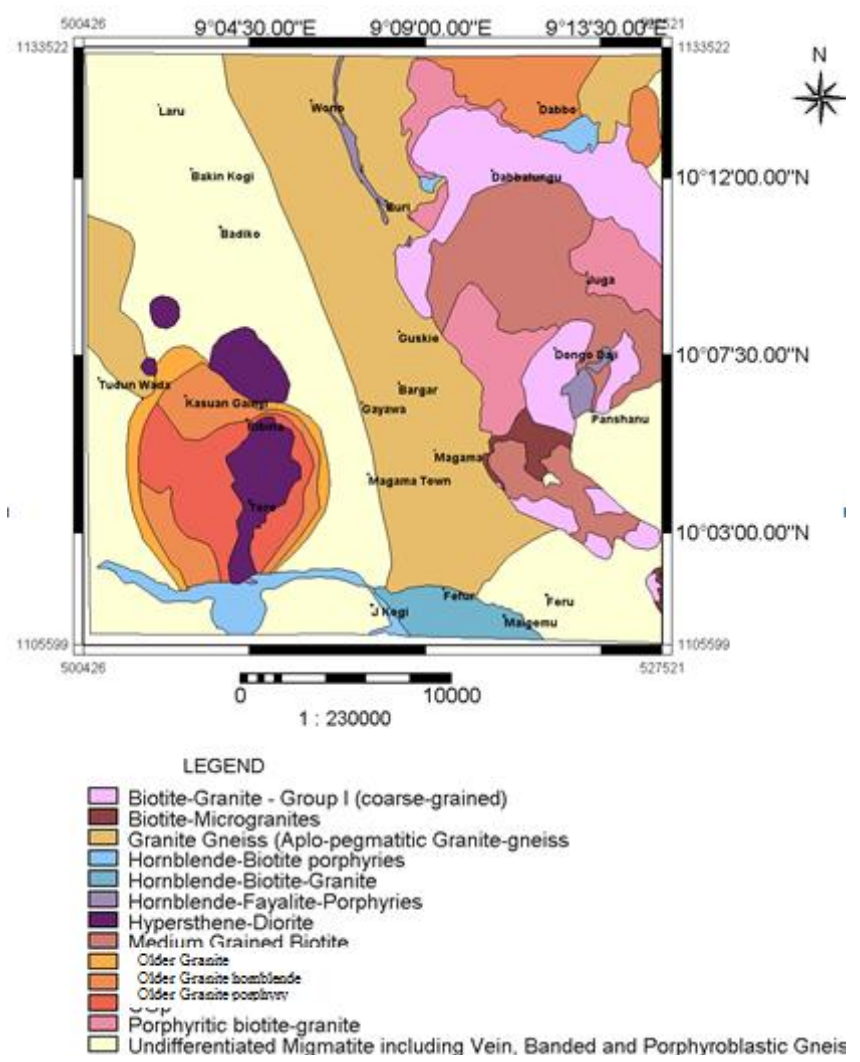

Fig. 3: Showing Digitized Geological Map of Toro and Environs

\section{Materials And Method}

Digitization of the maps was done on screen using the mouse on the scanned copies, in Ilwis2.0. Streams, settlements, outcrops and linear features were saved as layers and imported as themes for map composition in Arc view GIS 3.2a software,Georient 9 and Geocalculator were used for other structural plots. SURFER was also used for Digital Elevation Model. The following softwares were used.

\section{Statistics for the Dataset Used}

The summary of the statistical data on the bands is presented below (Table 1). This is useful in the image processing. In the selection of bands for composite, their degree of correlation is useful. The Optimum Index Factor technique (OIF) may help to overcome this problem. High OIF values indicate bands that contain much "information" (e.g. high standard deviation) with little "duplication" (e.g. low correlation between the bands). By using the OIF method, three band color composites can be evaluated on their effectiveness for display. From principal component analysis, the relative weighting of the individual bands can be seen.

Table 1.The variance-covariance matrix of the dataset for the area.

\begin{tabular}{|l|l|l|l|l|l|c|}
\hline $\begin{array}{l}\text { VAR/ } \\
\text { COVAR }\end{array}$ & Toro1 & Toro2 & Toro3 & Toro4 & Toro5 & Toro7 \\
\hline Toro 1 & 0.131 & 0.180 & 0.334 & 0.102 & 0.680 & 0.605 \\
\hline Toro 2 & 0.281 & 0.394 & 0.566 & 0.531 & -0.206 & -0.348 \\
\hline Toro3 & 0.415 & 0.228 & 0.286 & -0.684 & -0.403 & 0.253 \\
\hline Toro 4 & -0.720 & -0.223 & 0.603 & -0.088 & -0.205 & 0.134 \\
\hline Toro 5 & -0.069 & 0.156 & -0.284 & 0.441 & -0.528 & 0.645 \\
\hline Toro 7 & 0.457 & -0.829 & 0.205 & 0.193 & -0.105 & 0.121 \\
\hline
\end{tabular}




\subsection{Normalized Difference Vegetation Index (NDVI)}

In order to mask vegetation it is often useful to calculate a green vegetation index. The most commonly used vegetation index is the Normalized Difference Vegetation Index (NDVI) and can be used to obtain the threshold to mask vegetation in the ETM bands.

Normalized different vegetation index (NDVI) derived by satellite remotely sensed data is a good data source to study the spatial distribution of biomass. The index comes from ratio of near-infrared (NIR) and red bands (RED):

NDVI $=($ NIR-RED $) /(\mathrm{NIR}+\mathrm{RED})$

Or

NDVI $=($ ETM4-ETM3)/(ETM3+ETM4)

Where ETM4 represent near infrared band and ETM3 the visible red band

This property allows us a tool to see the detail of biomass distribution without topographic influence. The transformation for masking vegetation is according to the formula above

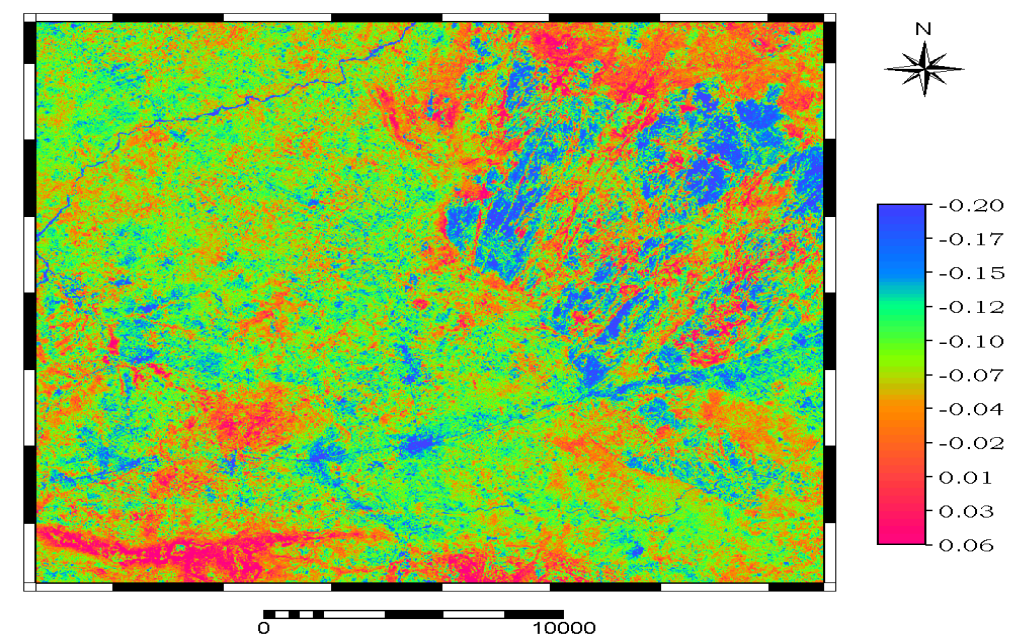

Fig. 4: An NDVI image for the study area showing vegetated areas ranging from red ( 0.06 threshold) to light green $(-0.12$ threshold) pending on the intensity of the vegetation.

\section{Lineament Analysis}

The lineament density was used to aggregate and calculate the total lengths per square kilometer using the appropriate Algorithm. The operation involves the digitization of linear and curvilinear features as segments from appropriately filtered ETM bands.

Bands 5 and 4 were best suited for picking linear features. Enhancement involves edge enhancement as well as directional filtering. These procedures made the structural features adequately visible for digitization. As these features were digitized, they were saved as layers. These layers are overlaid upon other segments such as roads, rivers and geological structures maps in other to identify lineaments that can be interpreted as geologically related (Short 2001).

Ilwis 3.1 and Golden Surfer were used for the lineament density analysis. Utilizing a pixel size of $2 \times 2$ sqaure kilometer, the lineaments per square kilometer is automatically calculated while the attribute of each segment such as serial number, length and orientation are automatically created and stored in vector attribute cells. Using the histogram function, the lineaments were automatically aggregated to be displayed in a rose plot.

\section{Iron oxides and clay mapping approach}

\section{Result And Discussion}

Supervised classification carried out resulted in the thematic maps showing iron-enriched (grey colouration) zones which have been interpreted to be as a result of the lateritization of the Younger Granite and Undifferentiated Basement (Fig. 5).

The major areas of interest have been sufficiently oxidize which may have a direct consequence of the alteration been sort after. This can grossly affect the reflectance of the minerals found on the surfaces which might have similar reflectance in most areas as the satellite crosses path over rock/vegetation exposures. 


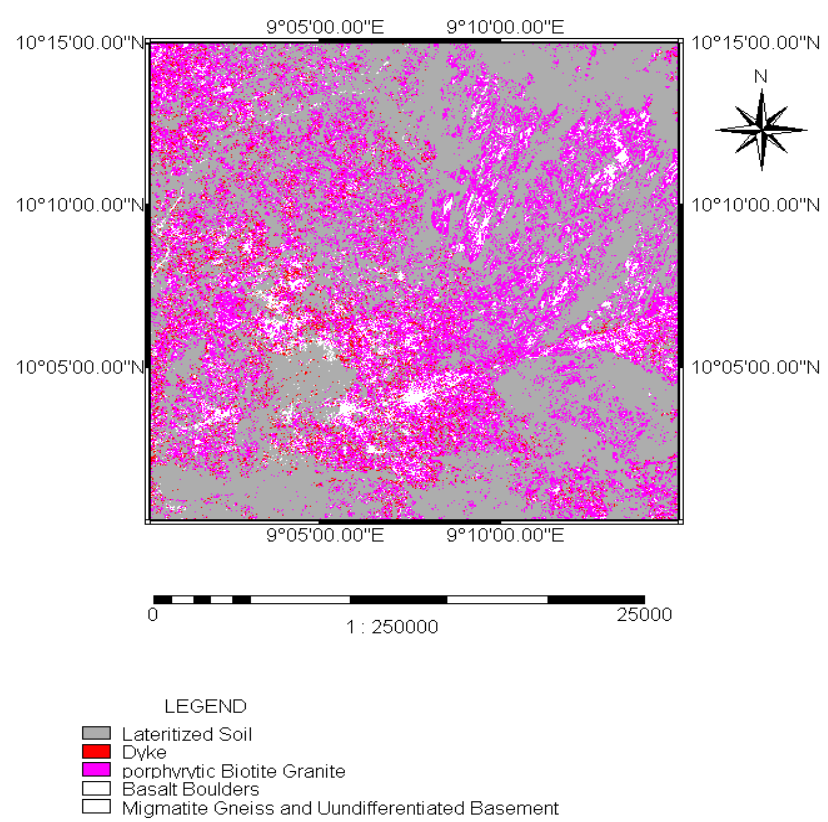

Fig.5: Supervised classification showing the Iron oxide and Undifferentiated Basement

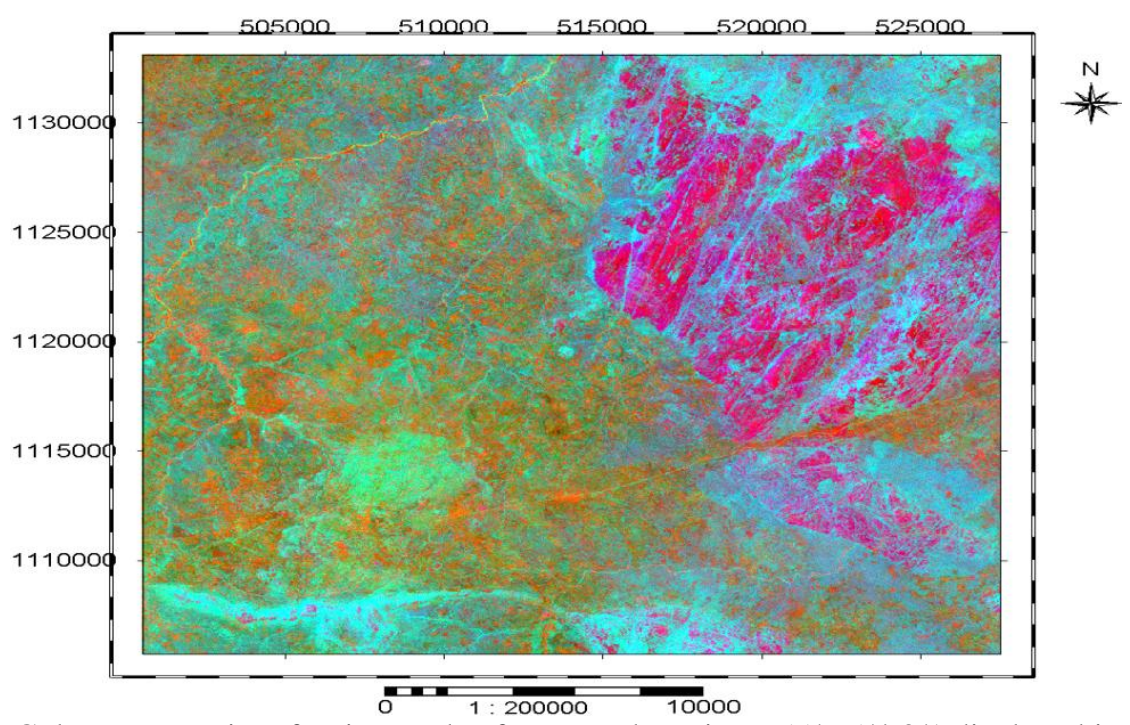

Fig...6: Colour composite of ratio Bands of Toro and Environs (5/7,5/4,3/1 displayed in RGB).

The color composite image of the map shown in Fig.6, flurocent green to white represent areas that have the highest concentration of clay while Red to Brown coloration on the map shows areas of Iron enrichment. Hence combines ratios 5/7 and 5/4, are areas of high clay as well as iron-enriched zones. All these attributes were carefully marked for ground verification. This implies that Toro and Environs is likely to be enriched with clay minerals with time as weathering advance (Feldspar weathering into kaolin).

\section{Lineaments}

Lineament density analysis have been the stock in trade in most geological applications of structural controls to mineralization such that, zones of intersections and trends are usually sort after in explorations because it is premised on the fact that mineralization is structurally controlled. Below is a Figure showing the extracted lineaments from the Satellite Imagery. 


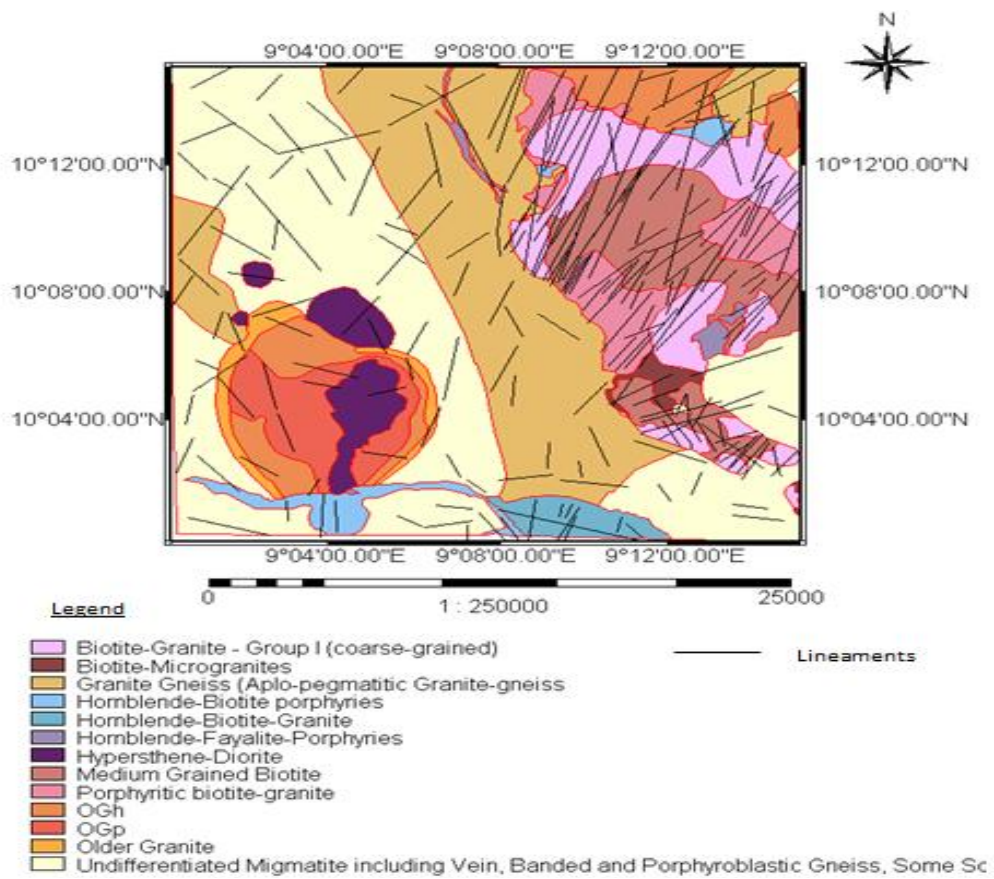

Fig.7: Lineament map extrapolated from remotely sensed image draped on Geologic Map.

A lineament is a mappable, simple or composite linear feature of a surface, whose parts are aligned in a rectilinear or slightly curvilinear relationship which differs distinctly from the patterns of adjacent features and presumably reflects a subsurface phenomenon (Oleary et al., 1976). Lineaments are believed to be the expressions of ancient, deep-crustal or trans-lithospheric structure which are periodically reactivated as planes of weakness during subsequent tectonic events. These planes of weakness and in particular the intersections may provide high-permeability channels for ascent of deeply derived mineralization fluids. Lineaments are considered as conduit and trapped zones for mineralizing fluids. These lineaments are therefore extracted from the available satellite image and interpreted.

Lineaments were extracted and interpreted from the Toro and Environs which had most concentration on Kwandonkaya Complex (Fig. 7) and around. The dominant trends is in the NE-SW direction while the minor trend are seen to trend NW-SE. A rose plot of the lineament from the Landsat Imagery is then plotted in Fig. 8.

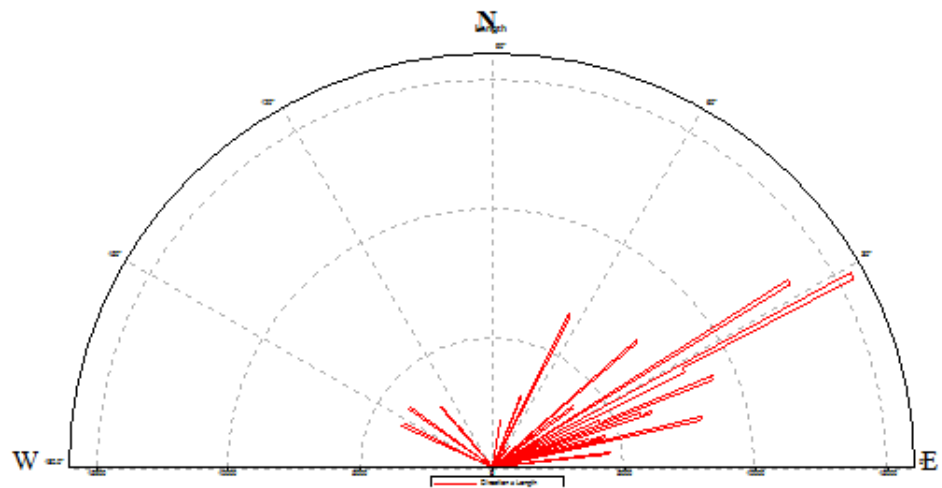

Fig. 8: Rose plot for Lineaments OfKwandonkaya Complex and Environs extracted from Land Sat ETM-7 showing the dominant NE trending direction.

\section{Digital Terrain Modeling}

As part of terrain visualization, it is essential to build up a digital terrain model as to enhance the work of an exploration geologist. The terrain model could help in assessing the extend of weathering of clay minerals which may get concentrated along weathered prone areas and down hill. Also since the Younger Granites intrude the Basement Complex, citing them from terrain model may be helpful. Fig.9, shows aerial photo of Toro and Environs indicating areas of high elevation with lighter tones while slopes in dark grey colour. The arrows shows direction of sloping of the terrain for flow of rivers and streams. Fig. 10, shows the general Terrain model on heights above sea-level with its contour draped above it. 


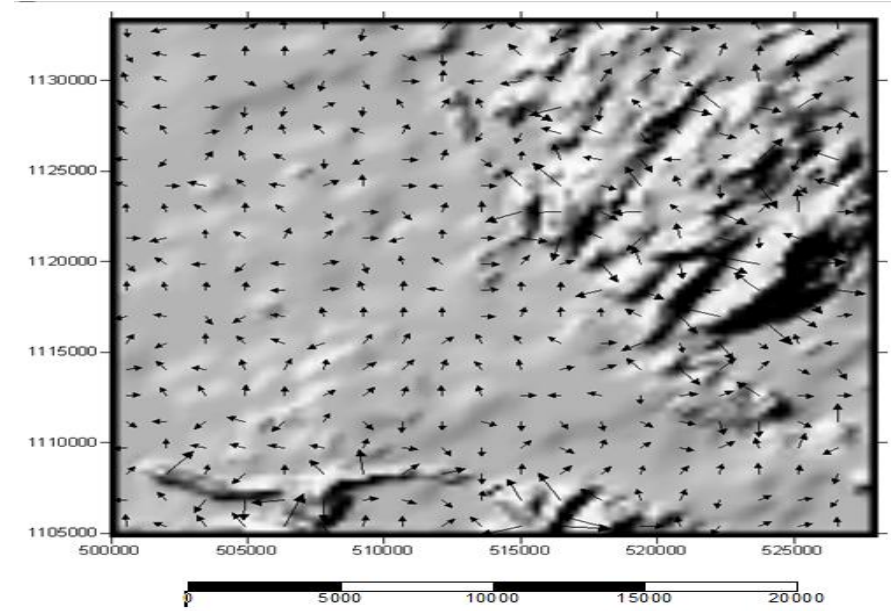

Fig.9. Shaded Relief Map showing the possible down stream washed plans which will concentrated clay and mineral aggregate at the plans

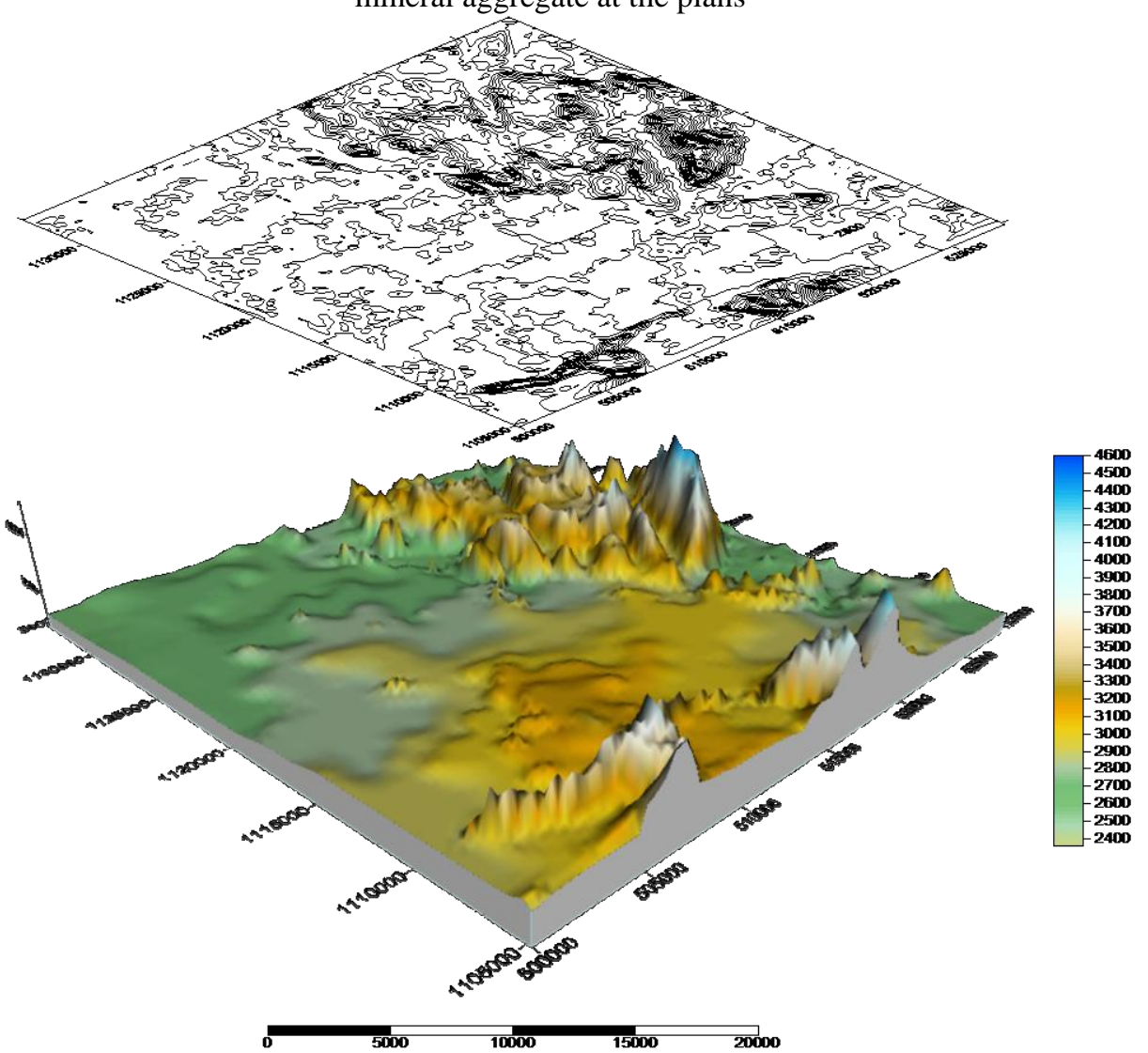

Fig.10.The digitized Digital Elevation Model (DEM of the Toro and Environs showing a better visualization of the intruded Younger Granite with highest peak in dip blue (Zeam Peak).

\section{Mineralization / Potential Map}

In the assessment of the mineral deposit enriched areas, various approaches were adopted. Mapping of rock outcrops, vegetation cover or concentration, and iron oxides were studied for building of the mineralization model. This was adopted because of the exposure of the rock units, digital terrain model and mass vegetation as well as river network which is seen to spread all around the study area.

A lineament density map was plotted (Fig.11), the threshold for high potential areas is set at $>8.5$, while 3-3.5 is considered intermediate, all values lower are classified low. The orientation statistics of the lineaments displayed by the rose plot show that major structural trends are NE - SW and NW - SE given an indication of the Pan - African footprint. 


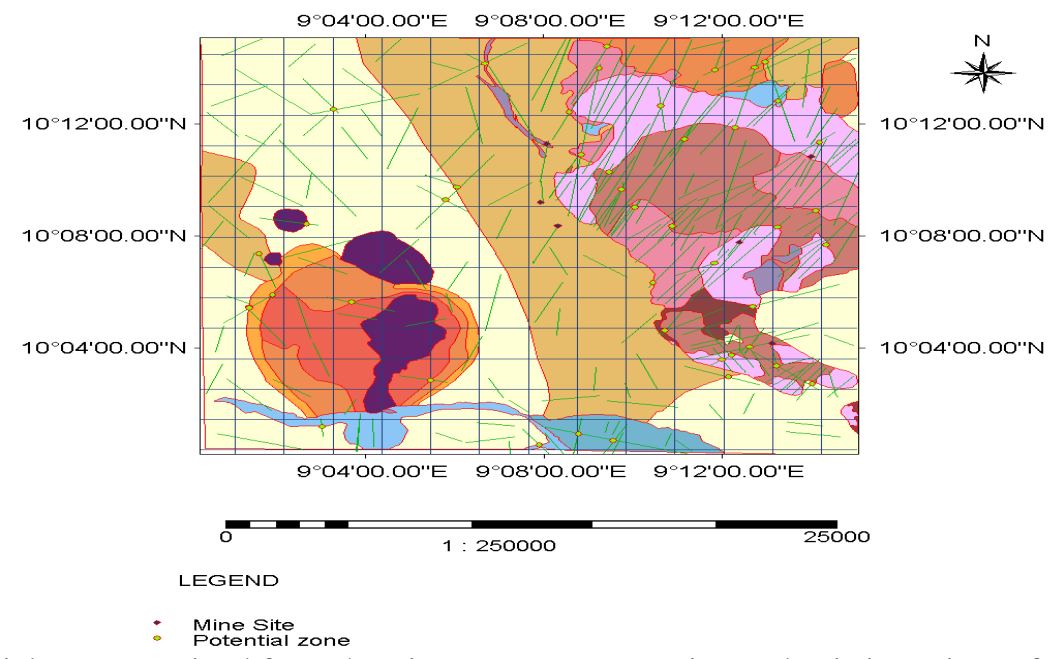

Fig. 11. Potential Zones Derived from the Lineament concentration and existing mines of the Study Area.

From the lineament density map above a probability graph for location of mine site was then plotted and the following conclusion was drawn; the probability of locating a mineralized zone within Toro and Environs is within a distance radius of $7.5 \mathrm{~km}$ from a point (Mining site or deposit). This was made possible using the Histogram table inllwis Academic software. From ground truth survey undertaken, the above postulation was right. The mine site at DogonDaji $\left(10^{0} 07^{\prime} 52.27^{\prime \prime} \mathrm{N} 9^{0} 12^{\prime} 24.33^{\prime \prime} \mathrm{E}\right)$ to that of East of Dutse Moro is in that approximate distance as well as that of Juga Northeast of DogonDaji.

Below if the Probability Graph for locating at least a point. From the plot below, the probability turn to be one (1) at a distance of $7.5 \mathrm{~km}$.

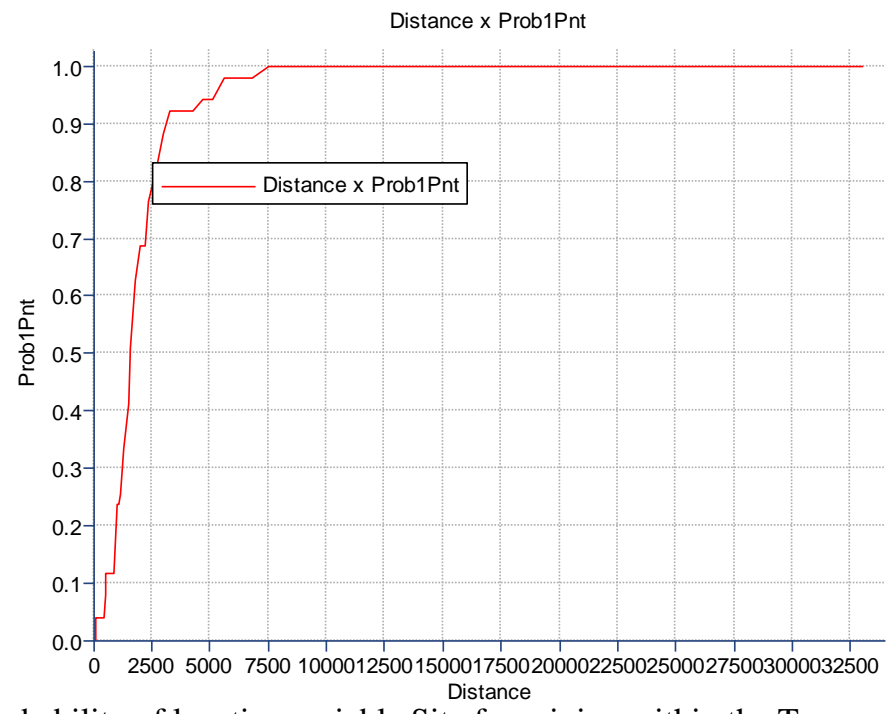

Fig.12: Probability of locating a viable Site for mining within the Toro and Environs

Toro and Environs has good exposures of rock surfaces which made lineament mapping to be very easy. A lot of lineaments could be seen from the Landsat Imagery (Fig. 5, 6 and 9). Intersection centers were interpreted as major controls units for mineralization as examined and related to literatures (fig. 11). A lineament density representing the total lengths per square kilometers was so set in order to give room for lineaments that are on a scale of 2 kilometer though no such lineament was found.

The lineament density map plotted indicate areas of high potential zones (Fig. 13). This confirms to the practical application of the selected analytical techniques, extracted lineament data from various remotely sensed images of different parts of Nigeria used. These include (a) the Landsat geological map of Nigeria $7^{0} 40^{\prime}$ North by Udoh (1988); (b) A map of the major fracture trends in the Nigeria Basement Complement by Oluyide (1988). From ground turthing, it was confirmed to coincide with some existing mining site found within the study area along DogonDaji and Juga, others were along Panshanu. From the plot, areas that fall within 10.5 to 7 threshold are highly mineralized while those that fall within 6.5 to 3 are intermediate zone and when related 
with the probability graph plot (Fig. 12) which say from a particular mine site, another mine could be located within a radius of $7.5 \mathrm{~km}$. Below are plates showing human activities at DogoDaji Mining site.

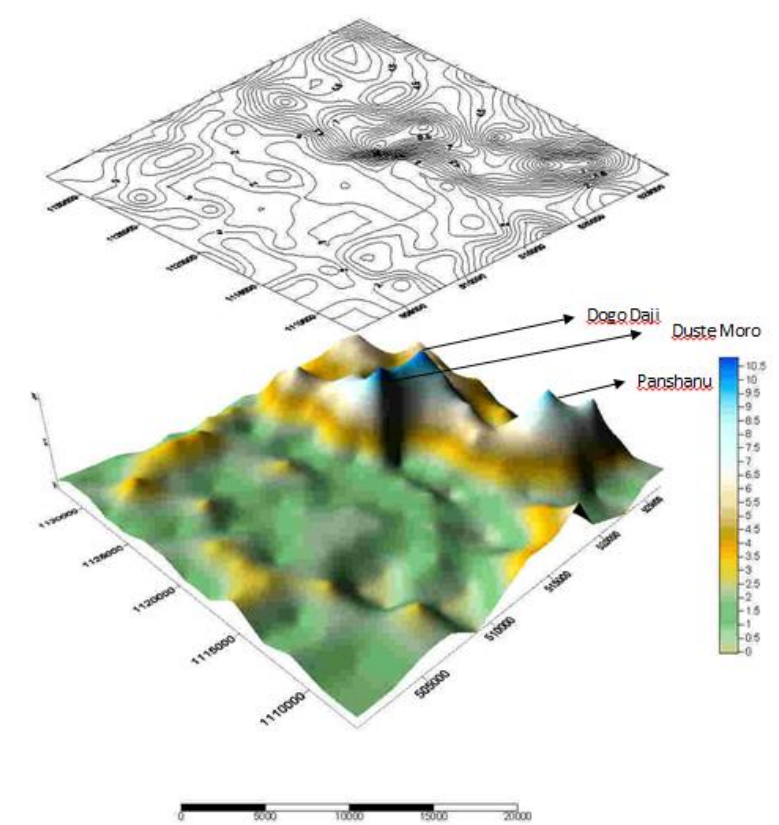

Fig. 13 Showing Threshold for high potential areas plotted from the lineament density map.

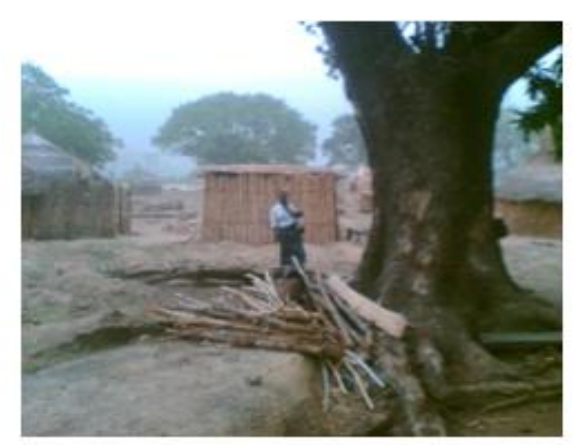

Plate 1 . Small scale Mining Camp at DogonDaji

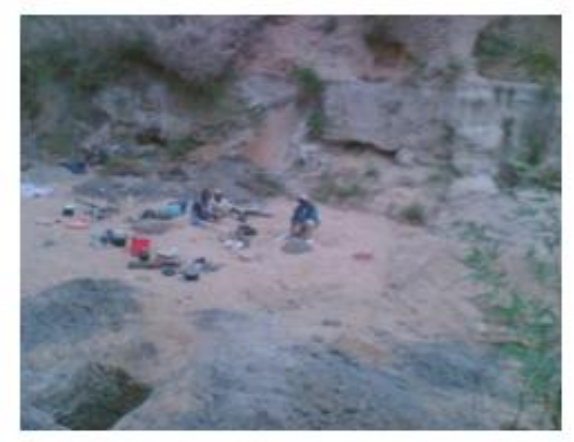

Plate 2. Small scale Mining site along river channel at DogonDaji

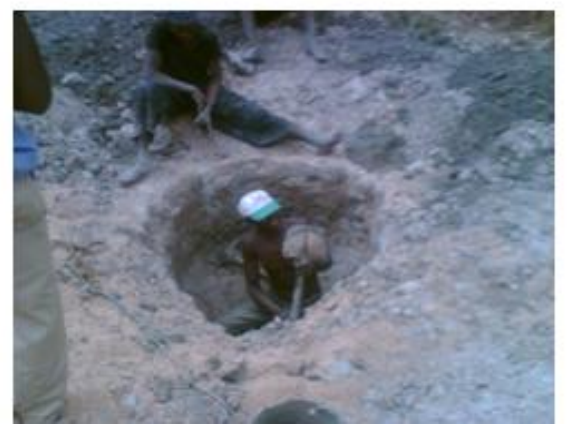

Plate 3 Mining in progress along river channel at DogonDaji 


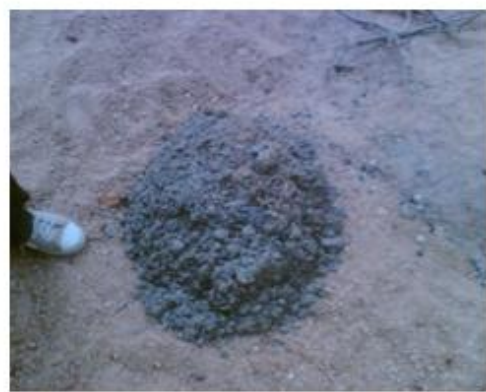

Plate 4 Cassiterite extracted from Mine

DogonDaji

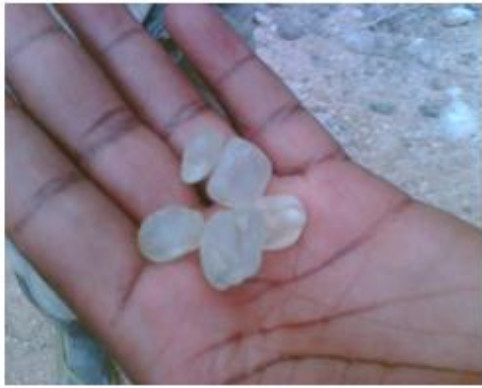

Plate 5Topaz extractedalong side during

mining from Mine at DogonDaji

\section{Conclusions}

The applicability of satellite remote sensing and especially Landsat_7ETM data in this research come to bear in mineral exploration by providing ample land cover information about lithologic mapping. The spectral properties of the soil cover types have proven extremely useful in delineating the boundaries of rock units around Toro and environs of Bauchi State.

The tectonic information brought about by the distribution of the lineaments has complemented the selection of the promising areas for detailed sampling. The biomass distribution was useful in the geologic study in this area. Following field confirmatory checks on the mine sites, the conclusion is drawn that digital image processing can be used in exploring for rock units, vegetated cover, potential mineralized zones and clay/oxide minerals.

\section{References}

[1] Ananaba, S. E., and Ajakaiye, D. E., (1987).Evidence of tectoniccontrol of mineralization in Nigeria from lineament density analysis.Int. J. Remote Sensing,Vol 8, No 10, pp 1445 - 1453.

[2] Bala, A. E., (2001). An evaluation of Landsat 5 thematic mapper data as a tool for Groundwater investigation in Basement Complex rock of Nigeria.Unpubl.Ph.D Thesis, Ahmadu Bello University, Zaria.

[3] Columbia River Resources Inc., (2003). Nigeria - Mining: Tantalum, Niobium and Rare Earth Element Mining Tantalite,Colombite, REE.www.mbendi.co.za/orgs/cm28.htm.

[4] Drury, (1990).Image interpretation in Geology. $2^{\text {nd }}$ Ed. Chapman \& Hall, London.283pp

[5] Huntington, J., (1998). Space Dependent Technologies - Remote Sensing in Mineral Exploration: Australian Academy of Technological Sciences \& Engineering. Academy Symposium1998.www.atse.org.au.

[6] Odeyemi, J. B., Anifowose, Y.B. and Asiwaju - Bello, Y.A. (1999).Multi-technique graphical analysis of fractures from remote sensing images of basement regions of Nigeria.Jour. Min. Geol. 33 (1), pp 9-21.

[7] Ologun J. A. A., (2007). Geological map of Biotite granite of Jos Plateau

[8] Oluyide, P. O., (1988). Structural trends in the Nigeria BasementComplex. In: Precambrian Geology of Nigeria by P. O. Oluyide (ed), Geology Survey of Nigeria publication, pp93-98.

[9] Sabins. F. F., (1987). Resource Exploration: REMOTE SENSING:PRINCIPLES AND INTERPRETATION $2^{\text {nd }}$ Ed. Freeman and Company. NY. 449p.

[10] Short, N. M., (2000).Remote sensing Tutorial. http://rst.gsfc.nasa.gov.

[11] Udoh, A. N., (1988). An interpretation of satellite imageries of Nigeria 7040’N. In: Precambrian Geology of Nigeria by P. O. Oluyide (ed). Geological Survey of Nigeria publication pp.99-102

[12] Udoh, A. N., (1989).An interpretation of satellite Imageries of Nigeria $7^{0} 40$. Precambrian Geology of Nigeria.GSN. Publ. pp327 